\title{
Left-sided incarcerated Amyand's hernia with cecum and terminal ileum: a case report
}

\section{Kebebe Bekele' \\ Desalegn Markos²}

'Department of Surgery, School of Medicine, Madda Walabu University, Bale Robe, Ethiopia; ${ }^{2}$ Unit of Neonatology Nursing, St Paul Hospital Millennium Medical College, Addis Ababa, Ethiopia
Correspondence: Desalegn Markos Unit of Neonatology Nursing, St Paul Hospital Millennium Medical College, PO Box 1234, Addis Ababa, Ethiopia Email desalegnmarkos@gmail.com
This article was published in the following Dove Press journal:

International Medical Case Reports Journal

19 October 2017

Number of times this article has been viewed

Background: Amyand's hernia, which is the presence of a normal or pathological appendix as a part of an inguinal hernia, is a rare clinical entity. We are reporting a very rare case of left-sided incarcerated Amyand's hernia with cecum and terminal ileum involvement.

Case presentation: A 4-year-old male child with left inguinal swelling of 2-year duration presented to Goba Referral Hospital. Two days before the patient visited our hospital, the swelling had become irreducible and caused severe groin pain. He had abdominal cramps, bilious vomiting, and mild abdominal distention, but passed feces. With the diagnosis of left-sided incarcerated inguinal hernia, the patient was investigated and prepared for surgical management. During the operative procedure, we identified the presence of appendix, cecum, and terminal ileum in the scrotum as the herniated component. After the sack was dissected, since there was also appendicitis, an appendectomy was performed. Then, high ligation of sack was done after cecum and ileum were reduced. After 3 uneventful postoperative days in the hospital, the patient was discharged. The patient was followed-up for 6 months, and he did not develop any complications.

Conclusion: Left-sided incarcerated Amyand's hernia with cecum and terminal ileum involvement is a rare clinical entity. Even though it is not common, appendicitis is one of the comorbidities that can be seen in patients with left-sided incarcerated Amyand's hernia with cecum and terminal ileum. Surgeons should have a high index of clinical suspicion and be aware of the potential involvement of appendix, cecum, and ileum as part of an incarcerated hernia during surgery, even in the left inguinal region. In this case, left-sided incarcerated inguinal hernia which involved inflamed appendix, cecum, and terminal ileum was successfully managed using an inguinal approach.

Keywords: Amyand's hernia, inguinal hernia, appendectomy, mobile cecum, ligation, case report

\section{Introduction}

Amyand's hernia is defined as an inguinal hernia containing vermiform appendix. It is one of the most infrequent pathologies of all inguinal hernias. ${ }^{1}$

Claudius Amyand was a French-born English surgeon who in 1735 successfully performed and recorded the repair of an inguinal hernia in an 11-year-old patient. The patient was found to have vermiform appendix in his hernia sac. Since then, the presence of the vermiform appendix in a hernia sac has been deemed an "Amyand's hernia."'

Amyand's hernia predominantly occurs on the right side. ${ }^{3}$ This is probably because right-sided inguinal hernias are more common than left-sided hernias, and the appendix is normally found on the right side. Left-sided Amyand's hernias are rare, and it has 
been suggested that they could be associated with a mobile cecum, situs inversus, or intestinal malrotation. ${ }^{4}$

Even though there are previous case reports on Amyand's hernia from overseas, ${ }^{1,5-11}$ there is a paucity of literature on left-sided Amyand's hernia with cecum and terminal ileum involvement from Africa, particularly Ethiopia. Therefore, we report a very rare case of left-sided incarcerated Amyand's hernia involving the cecum and terminal ileum in a 4-yearold male child.

\section{Case presentation}

A 4-year-old male child with swelling of left side of the inguinal region over a period of 2 years presented to Goba Referral Hospital. The swelling was initially reducible and gradually increased in size. Two days before the patient visited our hospital, the swelling became irreducible and caused severe groin pain. Additionally, he had abdominal cramps, bilious vomiting, and mild abdominal distention, but passed feces. He had no fever. On physical examination, the child was acutely sick looking and had a pulse rate of 144 beats per minute, respiratory rate of 30 breaths per minute, and temperature of $36.8^{\circ} \mathrm{C}$, as measured from the axilla. Besides, the abdominal examination revealed nontender flat abdomen that moved with respiration and a normoactive bowel sound on auscultation and tympanic during percussion. The swelling which was located on the left inguinal area was $10 \mathrm{~cm}$ by $12 \mathrm{~cm}$, had normal skin color, was not hot to touch, and irreducible manually but tender. Additionally, bowel sounds were heard in the scrotum. Both testes were palpable and were in the scrotum. With the diagnosis of incarcerated left-sided inguinal hernia, the patient was investigated with complete blood count and ultrasound. On complete blood count, white blood cell count was $11,200 / \mu \mathrm{L}$, with $83.7 \%$ granulocytes, $14.4 \mathrm{~g} / \mathrm{dL}$ hemoglobin, and 393,000 platelets. The patient's blood group was $\mathrm{B}^{+}$. An ultrasound examination revealed the presence of left-sided inguinal hernia which contained viable parts of the bowel. After the patient was prepared for surgical management, he was operated though a left inguinal incision. During the operative procedure, we identified the presence of appendix, cecum, and terminal ileum in the scrotum as the herniated component. The appendix was grossly inflamed, while the cecum was totally mobile and ischemic but returned to normal upon warm packing. The terminal ileum was viable. After the sack was dissected, since there was appendicitis, appendectomy was done. Then, high ligation of sack was done after the cecum and ileum were reduced. Postoperatively, we evaluated the patient for situs inverses, but on physical examination and in the abdominal ultrasound, his heart was on left side, liver on the right side, and spleen on left side. The underlying cause of this left-sided-incarcerated Amyand's hernia with cecum and terminal ileum involvement was the presence of a mobile cecum. After 3 days of uneventful postoperative stay in the hospital, the patient was discharged from the hospital. The patient was followed for 6 months, and he did not develop any complications.

\section{Consent}

Written informed consent was obtained from the patient's parent for publication of this case report.

\section{Discussion}

This incarcerated Amyand's hernia with cecum and terminal ileum involvement was found in a 4-year-old male child. Previous literature has also reported that Amyand's hernias are more common in men and can occur in people of all ages, from premature babies to elderly patients. ${ }^{12,13}$

One of the presenting symptoms in our patient was bilious vomiting and irreducible inguinal swelling. Different authors also supported the presence of bilious or nonbilious vomiting and irreducible inguinal swelling in similar cases. ${ }^{1,5,6,8-11}$

The Amyand's hernia with involvement of the cecum and terminal ileum that we reported was in the left side of the inguinal region and caused severe groin pain in the patient. On the other hand, other authors have reported that the majority of Amyand's hernia cases involved the right side of the inguinal region, and most of these patients also present with groin pain. A few cases of left-sided Amyand's hernia have been published. ${ }^{14,15}$ It was also identified that the contents of the hernia sac may comprises the small bowel, cecum, appendix, omentum, or ovary and fallopian tube. ${ }^{16}$ Therefore, surgeons should be aware of and keep in mind the potential presence of appendix, cecum, ileum, and other gastrointestinal and pelvic organ as contents of an incarcerated hernia during surgery, even if it is in the left inguinal region.

The presence of appendix, cecum, and terminal ileum in the scrotum as the herniated component, in our case, was identified during the intraoperative period. One study also reported that the diagnosis is usually made during the intraoperative phase when the patient undergoes surgical exploration. ${ }^{17}$ Contrary to this, it was reported that contrastenhanced computed tomography and a contrast enema have revealed the presence of the ileum and cecum and/or appendix within left-sided Amyand's hernias in some adult patients. ${ }^{18-20}$ Yoneyama et al, ${ }^{11}$ on the other hand, put forward the idea that it may not be practical to perform computed tomography or a contrast enema preoperatively to rule out 
Amyand's hernia in all pediatric patients with symptoms of an incarcerated hernia, and physical examination should be enough to prompt emergency operations in those patients. ${ }^{11}$

Even though the pathophysiology of appendicitis in Amyand's hernia is not clearly known, the appendix in our patient was grossly inflamed. Previous studies also supported that out of the total inguinal hernias, only $0.1 \%$ of patients had an inflamed appendix. ${ }^{21-24}$ This could be a result of either primary inflammation of the appendix causing edema of the internal inguinal ring or incarceration of a normal appendix by abdominal wall musculature. ${ }^{25}$

The underlying cause of this left-sided incarcerated Amyand's hernias with cecum and terminal ileum involvement was a mobile cecum. This finding is consistent with the case reports that showed underlying causes of Amyand's hernia. ${ }^{1,5-11,26}$

Losanoff and Basson created a classification scale to identify and treat Amyand's hernias. ${ }^{23,24} \mathrm{~A}$ type 1 hernia has a normal appendix in inguinal hernia, which is managed with a reduction and mesh repair. Hernia types $2-4$ are characterized by acute appendicitis within an inguinal hernia sac. In a type 2 hernia, an inflamed nonperforated appendix is seen. Type 3 hernia is characterized by a perforated appendix, while type 4 is complicated by intra-abdominal pathology. Hernia types 2-4 are managed with appendectomy and primary repair (without mesh). According to this classification, our patient had a type 2 Amyand's hernia with cecum and terminal ileum, and so he underwent appendectomy and primary repair of hernia without mesh.

\section{Conclusion}

Left-sided incarcerated Amyand's hernia with cecum and terminal ileum involvement is a rare clinical entity. Even though it is not common, appendicitis is one of the double burdens in patients with left-sided incarcerated inguinal hernia. Surgeons should have high index of clinical suspicion and be aware of the potential involvement of appendix, cecum, and ileum as the content of an incarcerated hernia during surgery, even if the hernia is in the left inguinal region. Leftsided incarcerated inguinal hernia, which involved inflamed appendix, cecum, and terminal ileum, in our patient was successfully managed using an inguinal approach.

\section{Disclosure}

The authors report no conflicts of interest in this work.

\section{References}

1. Gupta S, Sharma R, Kaushik R. Left-sided Amyand's hernia. Singap Med J. 2005;46:424-425.

2. Burgess PL, Brockmeyer JR, Johnson EK. Amyand's hernia repaired with Bio-A: a case report and review. J Sur Educ. 2011;68:62-66.

3. Pellegrino JM, Feldman SD. Case report: acute appendicitis in an inguinal hernia. $N J$ Med. 1992;89:225-226.

4. Breitenstein S, Eisenbach C, Wille G, Decurtins M. Incarcerated vermiform appendix in a left-sided inguinal hernia. Hernia. 2005;9:100-102.

5. Gupta N, Wilkinson T, Wilkinson A, Akhtar M. Left-sided incarcerated Amyand's hernia. Indian J Surg. 2007;69:17-18.

6. Cankorkmaz L, Ozer H, Guney C, Atalar M, Arslan M, Koyluoglu G. Amyand's hernia in the children: a single center experience. Surgery. 2010;147:140-143.

7. Khan R, Wahab S, Ghani I. Left-sided strangulated Amyand's hernia presenting as testicular torsion in an infant. Hernia. 2011;15:83-84.

8. Singh K, Singh R, Kaur S. Amyand's hernia. J Ind Asso Ped Surg. 2011;16:170-172.

9. Pun A, Khatri R. Left sided Amyand's hernia with sliding component. J Nepal Med Assoc. 2013;52:285-287.

10. Al-Mayoof A, Al-Ani B. Left-sided Amyand's hernia: report of two cases with review of literatures. Eur J Pediatr Surg Rep. 2014;2:63-66.

11. Yoneyama F, Tanaka H, Ono K, et al. An incarcerated appendix and the ileocecum within a left inguinal hernia in an infant. Surg Case Rep. 2015;1:61.

12. Schump elick V, Dreuw B, Ophoff K, Prescher A. Appendix and cecum. Embryology, anatomy and surgical applications. Surg Clin North Am. 2000;80:295-318.

13. House MG, Goldin SB, Chen H. Perforated Amyand's hernia. South Med J. 2001;94:496-498.

14. Anagnostopoulou S, Dimitroulis D, Troupis TG. Amyand's hernia: a case report. World J Gastroenterol. 2001;12:4761-4763.

15. Baldassarre E, Centozea A, Mazzei A, Rubino R. Amyand's hernia in premature twins. Hernia. 2009;13:229-230.

16. Puri P, Hollwarth M. Pediatric surgery: diagnosis and management. Berl Heidelb Springer. 2006:498

17. Weber RV, Hunt ZC, Kral JG. Amyand's hernia: etiologic and therapeutic implications of two complications. Surg Rounds. 1999;22:552-556.

18. Bo D, Mojin W, Wei Z, Lie Y, Zongguang Z, Yinghan S. Successful management of an incarcerated left-sided Amyand's hernia in a 63-yearold male. Chin Med J. 2014;127:980-981.

19. Kinoo S, Aboobakar M, Singh B. Amyand's hernia: a serendipitous diagnosis. Case Rep Surg. 2013;2013:125095.

20. Unver M, Ozturk S, Karaman K, Turgut E. Left sided Amyand's hernia. World J Gastrointest Surg. 2013;5:285-286.

21. Ballas K, Kontoulis T, Skouras C, Triantafyllou A, Symeonidis N, Pavlidis T. Unusual findings in inguinal hernia surgery: report of 6 rare cases. Hippokratia. 2009;13:169-171.

22. Psarras K, Miltiadis L, Baltatzis M, Pavlidis E, Tsitlakidis A, Symenodis N. Amyand's hernia-a vermiform appendix presenting in an inguinal hernia: a case series. J Med Case Rep. 2011;5:463.

23. Losanoff JE, Basson MD. Amyand's hernia: what lies beneath-a proposed classification scheme to determine management. Am Sur. 2007;73:1288-1290.

24. Losanoff JE, Basson MD. Amyand's hernia: a classification to improve management. Hernia. 2008;12:325-326.

25. Amyand C. Of an inguinal rupture, with a pin in the appendix caeci, incrusted with stone; and some observations on wounds in the guts. Philos Trans R Soc Lond. 1736;39:329-336.

26. Kaymakci A, Akilliouglu I, Akkoyun I, Guven S, Ozdemir A, Gulen S. Amyand's hernia: a series of 30 cases in children. Hernia. 2009;13:609-612. 
International Medical Case Reports Journal

Dovepress

Publish your work in this journal

The International Medical Case Reports Journal is an international, peer-reviewed open-access journal publishing original case reports from all medical specialties. Previously unpublished medical posters are also accepted relating to any area of clinical or preclinical science. Submissions should not normally exceed 2,000 words or

4 published pages including figures, diagrams and references. The manuscript management system is completely online and includes a very quick and fair peer-review system, which is all easy to use. Visit http://www.dovepress.com/testimonials.php to read real quotes from published authors.

Submit your manuscript here: https://www.dovepress.com/international-medical-case-reports-journal-journal 